\title{
USGS Chesapeake Science Strategy 2021-2025
}

The Chesapeake Bay ecosystem is a national treasure that provides almost $\$ 100$ billion annually of goods and services. The Chesapeake Bay Program (CBP), is one of the largest federal-state restoration partnerships in the United States and is underpinned by rigorous science. The U.S. Geological Survey (USGS) has a pivotal role as a science provider for assessing ecosystem condition and response in the Chesapeake watershed. Despite significant $\mathrm{CBP}$ accomplishments, the pressures of climate change and competing demands on land use and change require an acceleration of progress towards the 10 goals in the Chesapeake Bay Watershed Agreement. USGS Chesapeake studies are increasing efforts to provide integrated science and are engaging stakeholders to inform the multi-faceted restoration and conservation decisions to improve habitat for fish and waterfowl, and socio-economic benefits to the 18 million people living in the watershed.

\section{The USGS is implementing four integrated science themes (fig. 1):}

- Theme 1: Provide science for environmental management of stream health, fish habitat, and water quality.

- Theme 2: Assess the risks to coastal habitats and migratory waterbirds.

- Theme 3: Enhance landscape data and forecasting to inform watershed management.

- Theme 4: Integrate science and inform stakeholders.

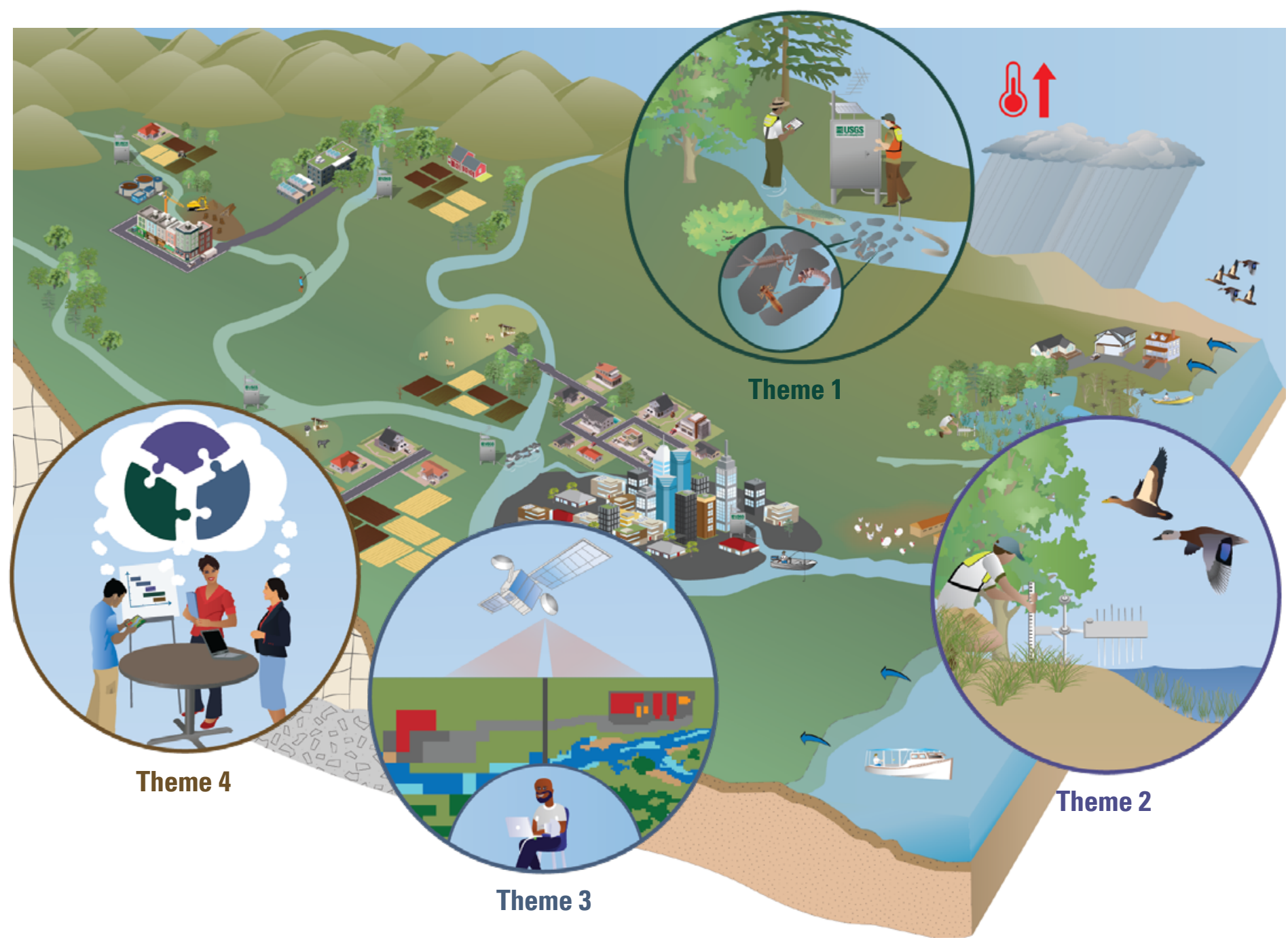

Figure 1. Conceptual diagram of the Chesapeake watershed depicting the four USGS science themes (see insets), as well as major environmental drivers, like climate change, land-use activities, and urban development. 


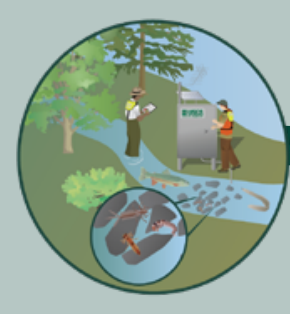

\section{Theme 1: Provide science for environmental management of stream health, fish habitat, and water quality}

The Chesapeake Bay watershed supports important recreational and commercial fisheries, which are valued at more than $\$ 20$ billion annually. However, portions of the watershed have declining fish populations and diminished fish health caused by poor water quality, loss of quality habitat and increased invasive species. The USGS science activities provide resource managers with an integrated understanding of how the various management efforts (restoration and conservation activities), environmental drivers (land-use and climate change), and stressors (elevated nutrients and contaminants) are affecting habitats for critical living resources (fish, stream health), and supporting economies (fisheries, boating, tourism, and agriculture) throughout the watershed.

USGS Chesapeake Bay studies are designed to provide a comprehensive approach to understanding the cumulative effects of drivers, stressors, and management actions on the habitat available for fish and wildlife, as well as benefits to people (fig. 2).

Land-use and climate change are drivers that affect landscapes and habitats across the Chesapeake watershed. Understanding their interactive effects and forecasting future conditions is critical to develop new restoration and conservation strategies.

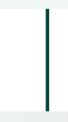

DRIVERS

Key stressors include elevated nutrients, sediment, and toxic contaminants, as well as flow alteration, increasing temperatures, aquatic diseases, and invasive species. While the impacts of individual stressors have been documented, managers need to understand the cumulative effects of multiple stressors on habitat and aquatic species.
Management strategies have been developed and practices are being implemented to reduce stressor effects. However, managers require better information regarding (1) the specific placement of these management practices, and (2) the ecosystem response to the practices.

\section{FISH, WILDLIFE, PEOPLE}

More than 3,600 species of fish, plants and wildlife inhabit the watershed. The USGS provides science to inform the management of recreational and commercial fish

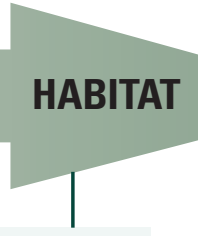

The Chesapeake Bay watershed boasts a tremendous diversity of habitat types. Science is critical to understand how habitat and aquatic conditions are changing in response to stressors and management actions. and waterbird species, as well as the water and lands that are vital to the 18 million people who live in the watershed.

FISH, WILDLIFE, PEOPLE

Figure 2. Understanding the effects of drivers, stressors, and management on habitat and living resources in the Chesapeake watershed.

Studies are designed to link management actions, drivers, and stressors with stream health, fish habitats, and aquatic conditions across a range of landscape types and biological indicators

Cold headwaters

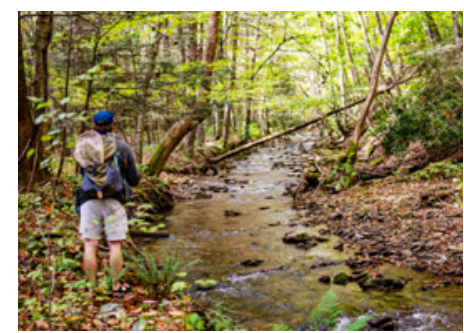

The USGS provides science on cold headwater streams to help restore and protect conditions critical for brook trout, which have great recreational, economic, and ecological significance.
Streams

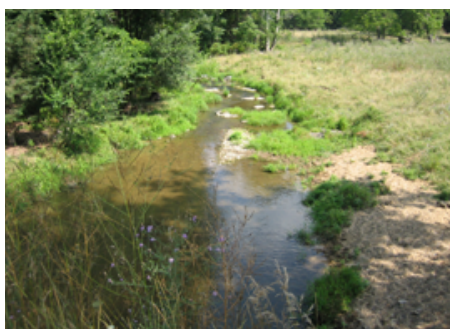

The USGS focuses on the stressors and management practices affecting the habitat quality and biological richness of smaller streams because most management efforts occur at the local level.
Rivers

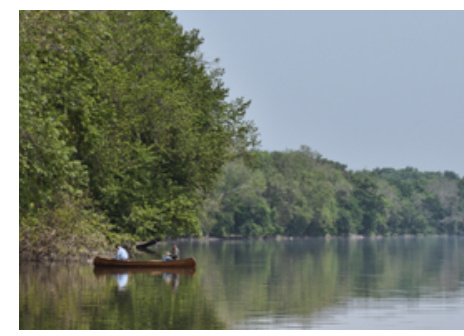

The USGS assesses how largeriver health and populations are affected by flow, water quality, and emerging threats. Large rivers in the Chesapeake watershed host a diverse collection of recreational and commercial fish species.
Watershed effects on estuaries

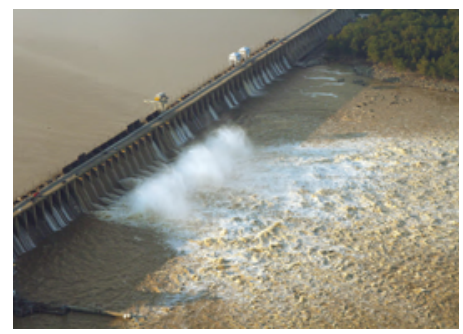

The USGS works to better link watershed actions to estuary response and recovery because the vast watershed, shallow waters, and extensive shoreline of the Chesapeake Bay is vulnerable to upstream changes. 


\section{Assessing regional stream health and fish habitat}

The degradation and loss of aquatic habitats threatens aquatic organisms, including many recreational, commercial, and ecologically important fish species in the Chesapeake Bay watershed. The USGS is developing regional assessments to predict stream health and fish habitat throughout the watershed and to forecast the changes in these habitats that could occur because of drivers like land-use and climate change (fig. 3). Mapping habitat distributions and providing spatial and temporal data on habitat stressors are critical to identifying and targeting appropriate conservation and restoration strategies.

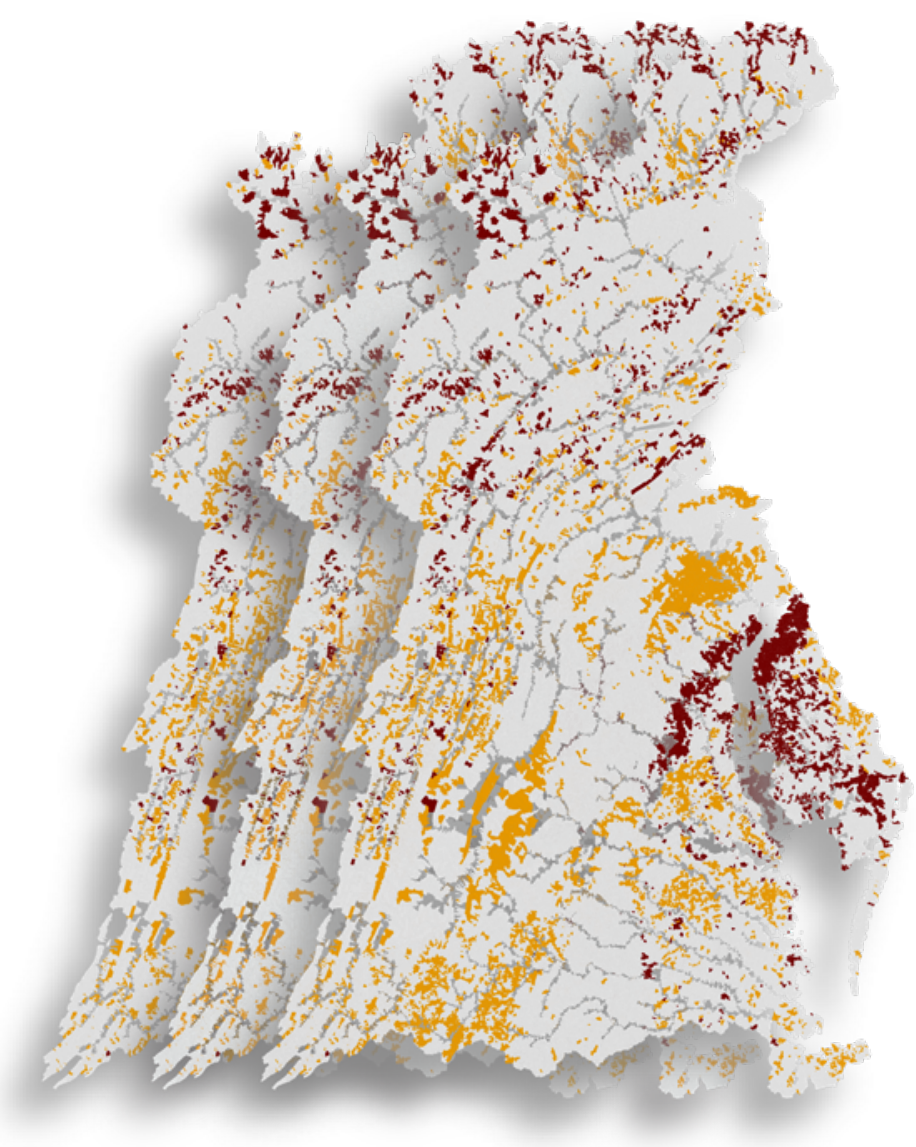

Figure 3. Graphic showing predicted 2090 change in stream health, based on several different land-use and climate-change scenarios (each image represents a different scenario). Red areas have predicted improvements in stream health, while yellow areas have predicted degradation in stream health under different projections. See Maloney and others, 2020, for more details.

\section{Describing status and trends throughout the watershed}

Status and trends analyses are essential to track how ecological conditions are changing across the watershed and help to provide indications of the effectiveness of restoration and conservation practices. The USGS is developing an understanding of both the status (current condition) and trend (trajectory of change: improving or degrading) for water quality (fig. 4), stream health, and fish habitat that informs targeting and effectiveness of management efforts.

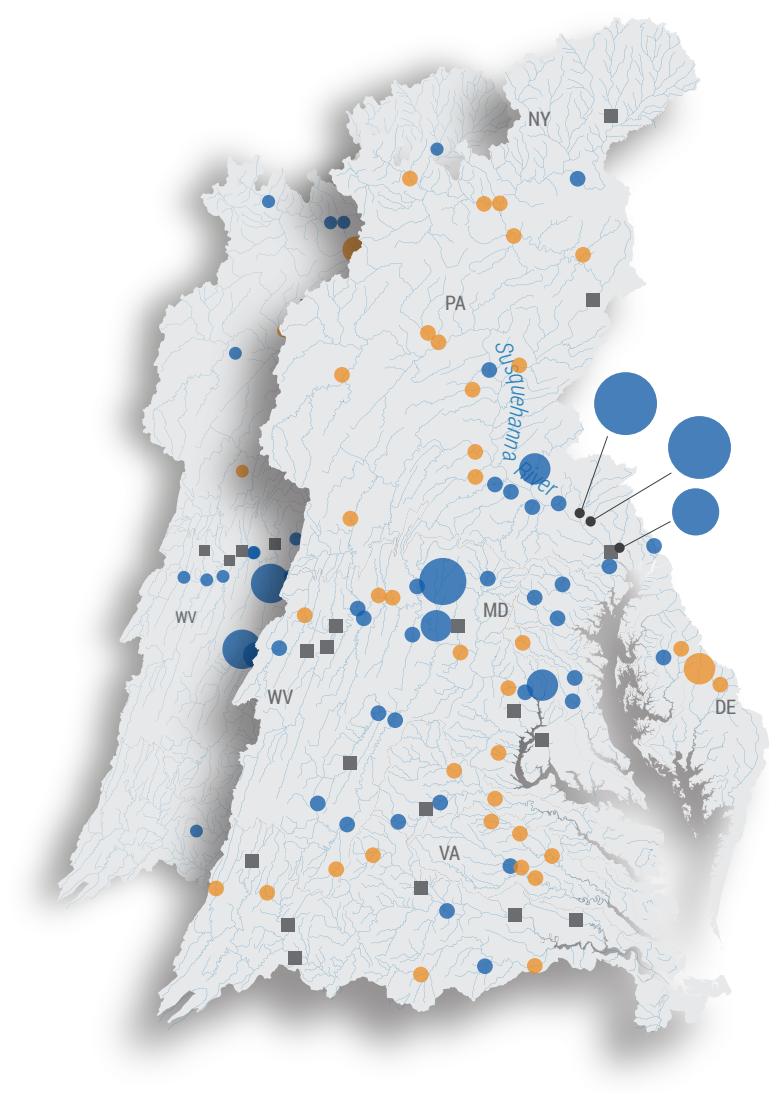

Figure 4. USGS leads the computation of water-quality loads and trends throughout the nontidal portions of the watershed to understand how conditions are changing and the potential response to watershed-management efforts. Presented are the changes in total nitrogen yield from 2009-2018 (blue markers indicate improving trends and orange markers indicate degrading trends); data from Moyer and Langland, 2020.

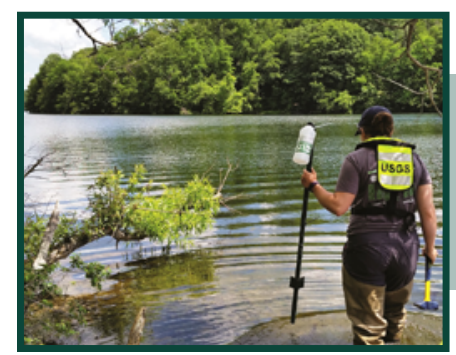

The USGS is the leader in streamflow measurement, water-quality monitoring, and change analysis throughout the nontidal portions of the watershed. By embracing uniform methods and a collaborative partnership approach, comparable nutrient and sediment data are collected to understand nutrient and sediment patterns throughout the basin. 


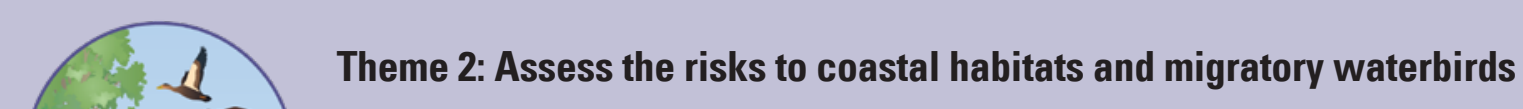

The coastal areas of the Chesapeake provide critical habitats for fish and crabs, migratory waterfowl, and space where nearly 10 million people live, work, and recreate. Balancing the ecological, recreational, and commercial demands and benefits within the coastal areas is extremely challenging, and efforts to do so are threatened by increasing rates of sea-level rise, changing storm frequency, coastal development, and emerging biological threats. The USGS science efforts are assessing the factors affecting the nearshore environment and its vulnerability to inform restoration and climate-adaptation efforts.

\section{Coastal habitats are threatened by sea-level rise}

The USGS is assessing the risks to coastal habitats by examining past changes and current conditions, and by forecasting potential future responses to land-use and climate change (fig. 5). The USGS is mapping and assessing the characteristics of coastal habitats to better predict their vulnerability or resiliency to sealevel rise and is preparing associated decisionsupport tools to inform restoration efforts. The USGS activities include (1) measuring land subsidence and elevation changes to forecast relative rates of sea-level rise, (2) describing the effects of these processes on marsh restoration, marsh migration, and (3) using paleoecology (exploring historical interactions between living organisms and their environment) to support long-term restoration, conservation, and adaptation efforts in these critical habitats.
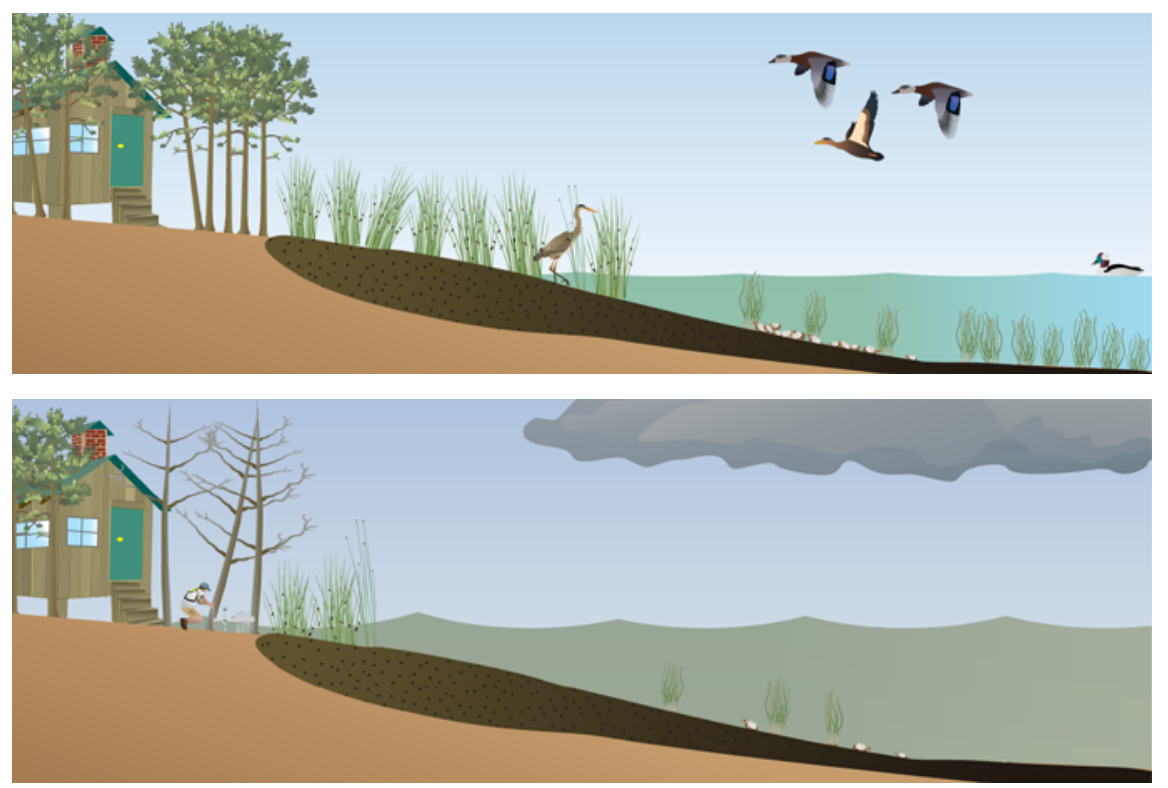

Figure 5. USGS studies are documenting the risks to coastal habitats, including the drivers and stressors that are affecting coastal systems. Top panel depicts a healthy, economically viable coastal system, compared to the bottom panel depicting a degraded coastal system that is affected by sea-level rise, increased coastal flooding, land erosion and inundation, as well as loss of habitat and living resources (marshlands, submerged aquatic vegetation, oysters, and waterbirds).

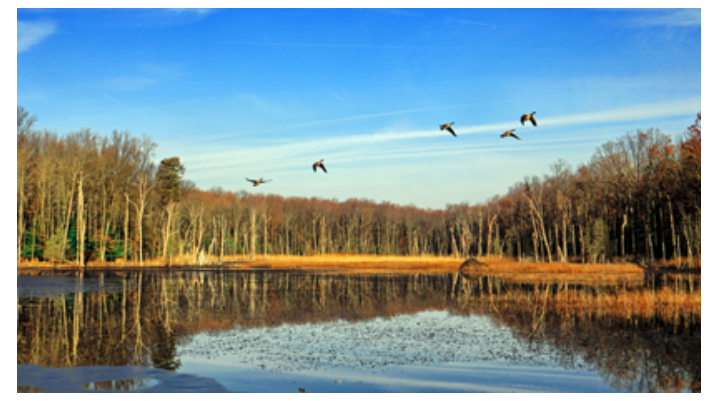

\section{Coastal factors affect waterbirds and their habitats}

The improved USGS understanding of coastal systems is also providing critical information on the factors affecting waterbird habitats. The USGS is assessing the availability of waterbird food resources in different coastal habitats, as well as the relative abundance and movement of the waterbirds within these coastal areas. There are emerging biological threats to waterbirds, including the effects of disease, harmful algal blooms, and newer contaminants. The USGS is increasing studies of these threats so resource managers can consider options to reduce harm to waterbirds.

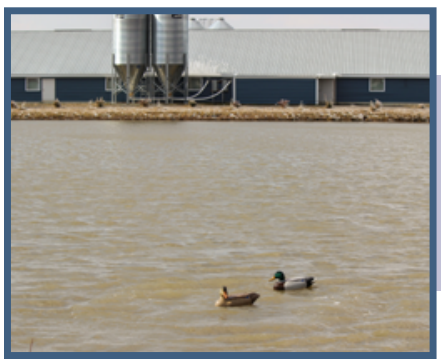

The USGS assesses the potential transmission of avian influenza from wild birds to domestic poultry to inform disease monitoring and planning biosecurity tactics, because of the importance of the poultry industry in the watershed. 


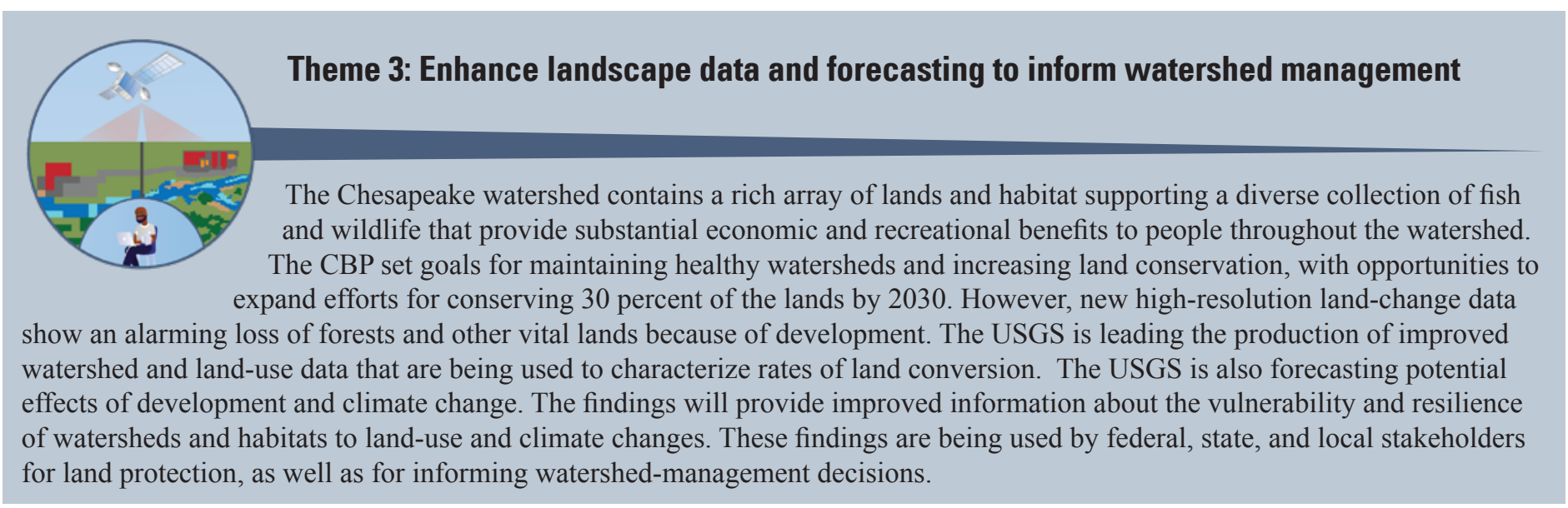

\section{High-resolution mapping to inform local decisions}

High-resolution information for the Chesapeake watershed allows for more focused decisions to protect and restore local lands and waterways. The USGS oversaw the production of high-resolution (1 meter) land-use data for the watershed (fig. 6). The USGS is now leading the follow-up effort to examine land-conversion rates, and where change is occurring throughout the watershed to help decision makers focus their land-protection efforts. The USGS is collaborating with partners to develop and apply improved information on watershed and stream characteristics to better understand the vulnerability and resiliency of streams and aquatic communities to land conversion and climate change.
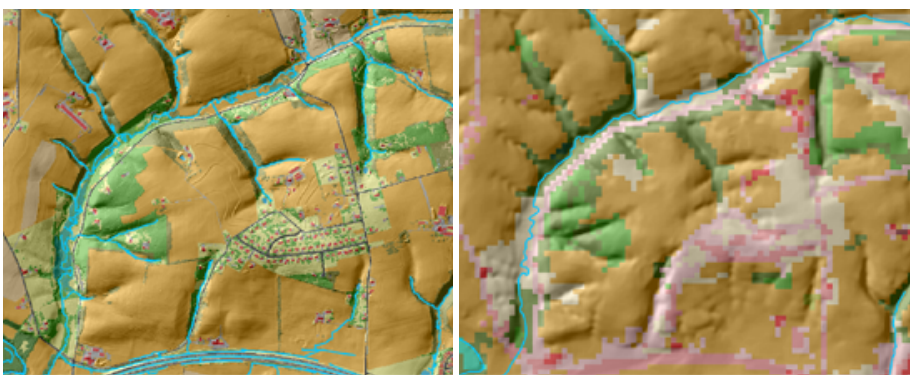

Figure 6. The USGS oversaw the production of high-resolution (1-meter) land-use data for the watershed (left), which greatly improved the spatial resolution of existing data (right) in support of local decision making. The high-resolution land-use image (left) includes the latest 2017 1-meter resolution land use and 1-meter resolution streams draped semi-transparent on a LiDARderived 1-meter hillshade. The righthand image includes the 2016 30-meter resolution National Land Cover Dataset and 1:24K National Hydrography Dataset flowline draped semi-transparent on a 10-meter resolution National Elevation Dataset.

\section{Forecasting change and informing land protection and use}

The USGS forecasts land-use changes to assess threats from land conversion on the health of watersheds and to more fully understand the combined effects of land-use and climate change on the Chesapeake ecosystem. The USGS Land-Change Model is being enhanced to simulate changing conditions in infill development, agriculture, and forests; accommodate the latest land-change monitoring and demographic data; and simulate scenarios consistent with global climate-change models. The analyses of the high-resolution watershed data, and forecasting scenarios, are used to inform land-protection and local-planning decisions (fig. 7).

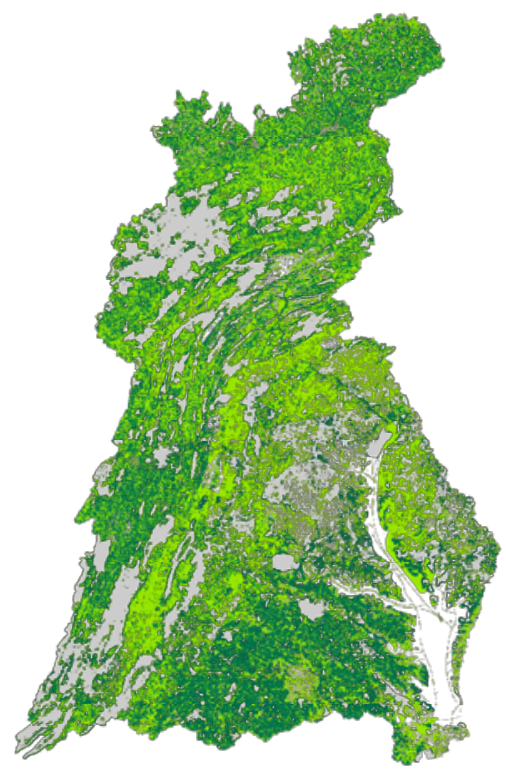

Figure 7. USGS watershed data and land-change forecasting are used to inform protection of vital lands. Map of most valued Chesapeake lands from Chesapeake Conservation Partnership, 2019.

Best management practice (BMP) data are used to help assess progress toward water quality and other CBP goals. The USGS is entrusted by multiple partners to access privacy-protected local BMP data to help explain water-quality changes and support deeper understandings of implications on stream health, vital habitats, and watersheds.

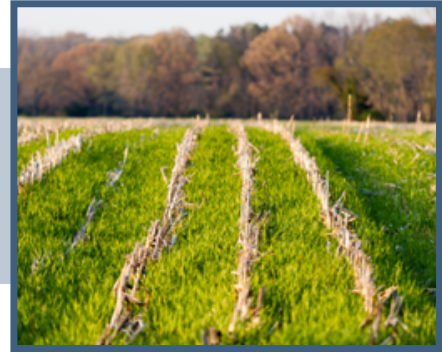




\section{Theme 4: Integrate science and inform stakeholders}

The USGS provides unbiased and non-regulatory science to the CBP stakeholders, and the Chesapeake Watershed Agreement commits to using science-based decision making to support the complex management decisions within the ecosystem. The ability of USGS to interact with stakeholders to address their science needs and translate findings to inform decision making is critical to achieving progress toward goals in the agreement. Many of the agreement goals are being addressed individually, but an integrated approach is required to understand how restoration efforts can benefit multiple goals. Therefore, the USGS conducts integrated science, working across multiple disciplines, to address the complex issues faced by land- and water-resource managers. The USGS is translating findings and engaging stakeholders to effectively inform decisions in the Chesapeake system, which can also apply to other national landscape and ecosystem management efforts.

\section{Integrating diverse disciplines across USGS Science Centers}

USGS Chesapeake studies bring together interdisciplinary scientists from across the country to work on the highest priority Chesapeake science needs (fig. 8). The USGS develops and shares scientific information throughout the Chesapeake community of scientists, managers, policy makers, and the public.

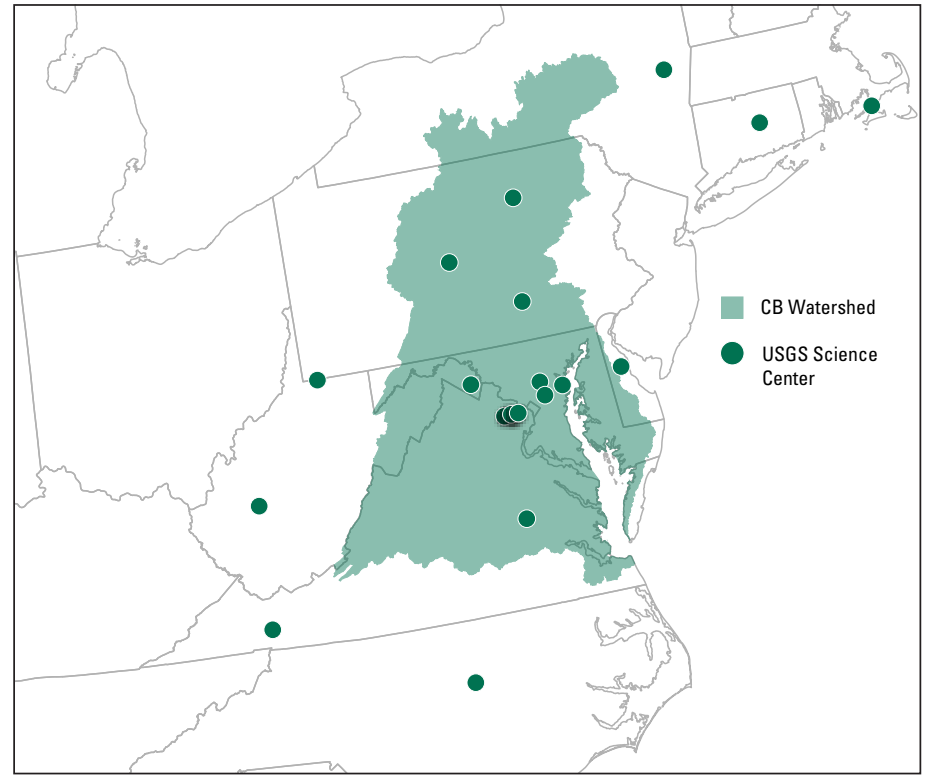

Figure 8. USGS integrates diverse scientific disciplines across multiple science centers to inform decisions by stakeholders.

Acknowledgments: We thank the USGS Chesapeake Science Team for assistance developing this fact sheet and for contributing primary sources of information.

Suggested reference: Hyer, K., and Phillips, S., 2021, USGS Chesapeake Science Strategy 2021-2025: U.S. Geological Survey Fact Sheet 2021-3037, 6 p., https://doi.org/10.3133/fs20213037.

Science communication, layout, and design: Bill Dennison, Dylan Taillie, Sky Swanson, University of Maryland Center for Environmental Science

Support: This material is based upon work supported by the U.S. Geological Survey under cooperative agreement No. G20AC00106.

Photo credits in order of appearance: Will Parson/Chesapeake Bay Program (CBP), Dylan Taillie, Ken Hyer, Victoria Pickering, Wendy McPherson (USGS), Elizabeth Nystrom, Timothy Polhaus, Jefferey Sullivan (USGS), Will Parson/ CBP

For more information regarding USGS Chesapeake studies visit: https://www.usgs.gov/centers/cba

\section{Translating science to inform complex decisions}

The USGS interacts with the CBP teams working to achieve the 10 goals and 31 outcomes of the Chesapeake Watershed Agreement, many with deadlines of 2025. By engaging the CBP stakeholders, USGS understands their science needs and conducts relevant investigations. As USGS studies are published, we translate and visualize key findings and interact with stakeholders to apply results to inform decisions through an adaptivemanagement process (fig 9). In addition, approaches and findings from USGS Chesapeake studies are applied to other regional ecosystem studies across the Nation.

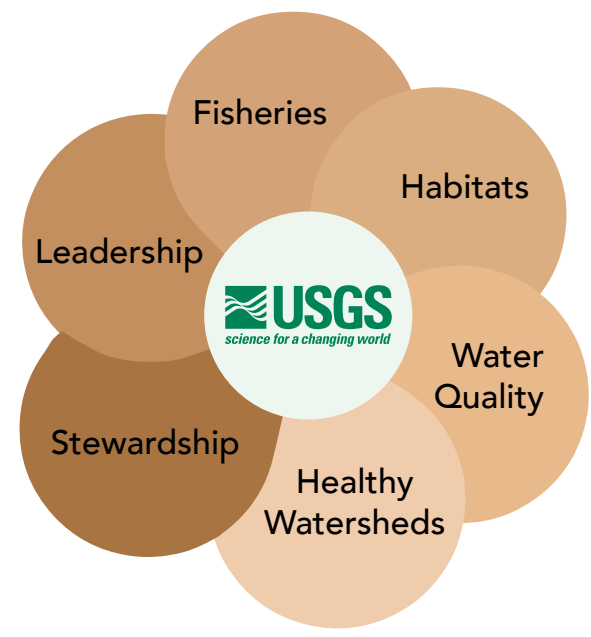

Figure 9. The USGS interacts with the six CBP Goal Teams to understand the complex relation between goals and to inform management decisions.

\section{Selected references:}

Chesapeake Conservation Partnership, 2019, Marking Milestones, accessed on April 08, 2021, at https://www.chesapeakeconservation.org/wp-content/ uploads/2019/08/CCP_publication_SD_FD-R-FINAL.pdf.

Maloney, K.O., Krause, K.P., Buchanan, C., Hay, L.E., McCabe, G.J., Smith, Z.M., Sohl, T.L. and Young, J.A., 2020, Disentangling the potential effects of land-use and climate change on stream conditions: Global Change Biology, 26(4), pp.2251-2269

Moyer, D.L., and Langland, M.J., 2020, Nitrogen, phosphorus, and suspended-sediment loads and trends measured at the Chesapeake Bay Nontidal Network stations: Water years-1985- 2018 (ver. 2.0, May 2020): U.S. Geological Survey data release, https://doi.org/10.5066/P931M7FT.

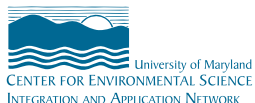

